\title{
El (no) lugar de la filosofía en la sociedad
}

YAMANDÚ ACOSTA

Universidad de la República, Montevideo, Uruguay

RESUMEN: Desde los presocráticos, la filosofía se ha configurado como una actividad distinta al lucro y al poder. Está en un "no-lugar" con respecto a las dinámicas de la competencia económica y de la carrera por las ganancias políticas. Sin embargo, esta

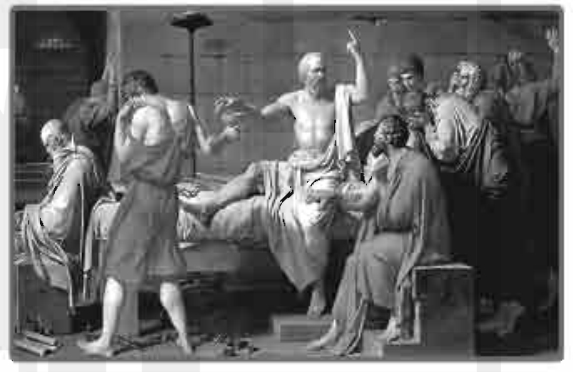
situación no conduce a la filosofía a una actitud desinteresada, por no decir indiferente, ante la realidad. Antes bien, es condición necesaria para su crítica al poder.

ABSTRACT: Since pre-socratic philosophers, Philosophy has been an activity that distinguishes itself from profit and power. It is located in a "non-place" regarding the economic and politic competitions. Nevertheless, this does not lead Philosophy to indifference toward reality. Moreover, it is a necessary condition to its critic to power. 
Mileto, se ubicaba entre aquellos que se limitaban a contemplar lo que pasa, que él era un filósofo.

Mientras competidores y vendedores están activamente articulados en determinada forma de negocio, el filósofo está, por el contrario, instalado en el ocio desde el cual ejerce la teoría; es decir, la contemplación que solamente produce una visión del mundo ("theorein" = ver, contemplar). El filósofo se compromete con su lugar y su tiempo solamente como un testigo de lo que acontece en la vida de la sociedad, a la cual le aporta una visión de conjunto desde la distancia proporcionada por el ocio que garantiza que la misma sea ajena a los juegos de intereses que se juegan en el mundo de los negocios.

\section{Parménides: la identidad entre el pensar y el ser y el develamiento de la verdad}

E n el célebre poema filosófico, la diosa enseña a Parménides que, no obstante la pluralidad y el cambio aparentes a los sentidos, "ser y pensar son una y la misma cosa", por lo que la contemplación de la verdad de lo que acontece, que surge de la anécdota de Tales como el aporte propio de la filosofía, no solamente implica el distanciamiento de los negocios en el ocio contemplativo, sino también el discernimiento de lo aparente para el develamiento de la verdad ("alétheia") con los ojos de la razón ("logos"). La visión de conjunto de lo que pasa, en cuanto propiamente tal, es decir en cuanto teoría, implica el esfuerzo de develar con la razón la verdad oculta del ser tras el mundo de apariencias al que los sentidos nos ligan.

No obstante, físicamente, el filósofo esté como espectador a cierta distancia del espectáculo que la sociedad desarrolla ante sus ojos, de 
acuerdo a la anécdota de Tales, la misma resignificada a la luz de los principios de la filosofía de Parménides implica que el filósofo, o lo que lo hace propiamente tal —es decir, el ejercicio de la razón- expresa el discurso verdadero o único discurso posible sobre el ser (incluyendo la dimensión social, que no es lo otro de la dimensión natural, sino constituyente de la misma), desde el centro mismo del ser (natural, social, racional), con el cual coincide de un modo ontológicamente a priori. La filosofía, en cuanto develamiento y enunciación de la verdad, no está en algún lugar del ser, sino en el sentido en que es la otra cara del ser (natural y social) mismo, en cuanto pensar. Queda férreamente argumentada la unicidad e inmutabilidad del ser (social), legitimada por ese pensar que en su unicidad e inmutabilidad está legitimado por el ser, desde que "ser y pensar son una y la misma cosa".

\section{Platón: el filósofo y el político. El mundo de las ideas y la caverna (la academia y el ágora).}

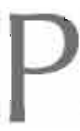

arménides afirmó el ser y su identidad con el pensar, nihilizando el devenir. Platón afirmó el ser y la unidad, afirmando y explicando al mismo tiempo el devenir y la multiplicidad: tal es la virtud de la que se conoce como teoría de los dos mundos, que encuentra una representación casi fotográfica en el célebre pasaje del Libro VII de La República, conocido como la alegoría de la caverna, del que, casi sin excepción todos los que hemos pasado por los cursos de filosofía en la enseñanza media, hemos tenido al menos alguna noticia.

La riqueza del recordado pasaje habilita muchas lecturas fermentales. Aquí interesará destacar que el lugar de la filosofía está en el mundo de las ideas o esencias ("eidos") eternas, únicas, perfectas e inmutables, mientras que el mundo de la caverna, habitado por la multipli- cidad de los seres humanos (la sociedad), es en realidad el lugar de la política, en la que el filósofo como político (el filósofo-rey) es el que mejores garantías puede ofrecer en los términos del buen gobierno, capaz de asegurar el orden ("cosmos") de la sociedad frente a la amenaza latente del desorden ("caos"), por la afirmación y reproducción de la comunidad ("polis"), articulación asimétrica entre la estirpe de los que gobiernan, la de los que ejercen la defensa y la de los que producen con su trabajo los bienes de consumo que materialmente hacen posible la vida de la comunidad.

Esto quiere decir que el filósofo como filósofo habita en el mundo de las ideas, mientras que el filósofo como político, como miembro de la "polis", regresa a la caverna de la que salió como filósofo para gobernar orientando a la diversidad 
y eventual conflictividad de la sociedad, en el sentido de la unidad, armonía y perfección de las ideas que solamente él conoce en plenitud. El deber del filósofo para con la comunidad que lo formó como tal lo obliga por responsabilidad con la comunidad (esto es, por responsabilidad política) a articularse con la comunidad desde el lugar de su gobierno. El filósofo, y con él la filosofía por las mediaciones del político y la política, adquiere con legitimidad un lugar central en la sociedad para reproducirla a imagen y semejanza del orden jerárquico e inmutable de las ideas. Esto es un orden fundado en la idea-valor del Bien y por lo tanto un orden bueno y también verdadero, justo y bello frente al cual cualquier pretensión alternativa solamente podrá ser la amenaza disolvente del caos, la sustitución del bien por el mal, de la verdad por la falsedad, de la justicia por la injusticia y de la belleza por la fealdad. El sentido último de la filosofía en la sociedad a través de la política es la deslegitimación e inhibición de toda alternativa como estrategia de reproducción y consolidación de un orden que, en tanto orientado por referentes eternos inalcanzables, se eterniza como orientación.

Cuando el filósofo actúa como político, legitima su actuación en términos objetivos porque tiene el conocimiento que le permite orientar a la sociedad en el buen rumbo y también en términos subjetivos, porque hace esto por deber para con la sociedad que lo ha formado y no por inclinación.

Así como cuando actúa como político no deja de ser filósofo y le da a la filosofía su dimensión política en la orientación de la sociedad, tal vez cuando actúa como filósofo no deja de ser político y le da a la política su dimensión filosófica en la orientación de la academia; hace de la filosofía la política por otros medios, hace de la academia el espacio de su ejercicio de poder filosófico-político, y, tras la pretensión de haber separado el régimen de verdad de la academia del régimen de poder de la sociedad, tal vez no ha hecho sino aportar a la reproducción del régimen de verdad y poder de la totalidad, de la que la comunidad política y la comunidad académica hacen parte.

\section{Descartes y Kant: del yo pensante al sujeto trascendental}

- I (no) lugar de la filosofía a par-

- tir del siglo XVII —en que tras la extensa e intensa mediación mediación del teocentrismo medieval ha superado el cosmocentrismo antiguo en el antropocentrismo de la modernidad - es la subjetividad del sujeto humano, aunque vaciada de humanidad.
Así, el ego cógito de Descartes remite a la sustancia pensante o alma, que existe por sí misma y que no precisa del cuerpo para existir, tal como surge de la tesis cartesiana "pienso, luego existo". A partir de la verdad fundadamente tal de acuerdo al criterio cartesiano de la evidencia racional que habilita la verdad 
por la mera intuición de la razón, queda abierta la posibilidad de la verdad por demostración "more geométrico", no habiendo nada por lejano y complejo que pudiera ser, que en principio no pueda ser conocido por esta razón filosófica metafísicamente fundamentada en el yo pensante titular de la razón y su capacidad intuitivo-demostrativa. Alguna lectura de la tercera regla del método permite además entender que la capacidad de la razón del yo pensante no se limita a conocer intuitivo-demostrativamente, minimizando la posibilidad del error si se atiene a los pasos del método, sino que además es capaz de concebir un orden en las cosas distinto a aquél que poseían por naturaleza $y$, en tanto este orden es racional desde que responde al sujeto titular de la razón, al ser teóricamente factible, quedan establecidas las condiciones necesarias, no obstante no suficientes, para que sea técnicamente factible.

Aquí el paradigma contemplativo de la antigüedad comienza a tener un quiebre que será cada vez más visible. El sujeto moderno - a diferencia del sujeto antiguo que contemplaba el mundo ("cosmos") orden) para entenderlo y aceptar su lugar en el mismo a los efectos de no provocar el caos - se orienta ahora a entender el mundo desde sus primeras causas y principios para intervenir en él y construirlo a su imagen y semejanza.

El plan del sujeto humano como creador del mundo desplaza tanto a la idea griega del mundo eterno como a la idea judeo-cristiana del mundo creado por el Dios eterno. Tales son el sentido y la proyección de la razón metafísica-filosóficacientífica-técnica que se expresa en Descartes como paradigma filosófico fundante de la modernidad en el que el sujeto humano procura ocupar el lugar de Dios.

Este sujeto pensante titular de la razón es en Descartes individual y universal al mismo tiempo, desde que la razón es "la cosa mejor repartida en el mundo". Pero el lugar estricto de esta razón es la sustancia pensante, por lo que el lugar de su actividad pensante metafísico-filosófico-científico-técnica es trascendente respecto del cuerpo del titular individual de la razón, así como respecto de la eventual relación de este cuerpo con otros cuerpos humanos o no humanos, lo cual determina la pretensión de exterioridad respecto de toda corporalidad, toda naturaleza y toda historia. Por lo que el horizonte de emancipación humana que él mismo indudablemente abre se ve tensionado por el horizonte de dominación de lo humano en su condición corporal-natural, así como del mundo natural-corporal en todas y cada una de sus expresiones y también como conjunto, que lo acompaña y que llega a imponerse invisibilizado tras la visibilidad del primero como horizonte legitimador.

El sujeto de la razón y por lo tanto de la filosofía y con ello la filosofía misma, está por fuera y por encima de lo real-natural y en 
consecuencia de lo real-social, por lo que la tensión emancipacióndominación, en la que el segundo horizonte se impone invisibilizado y legitimado por el primero, tiene sobre la sociedad efectos de dominación que se pretenden de emancipación, que se pretenden absolutamente racionales desde el pretendido no lugar de la filosofía en la sociedad.

Con Kant, el sujeto del racionalismo cartesiano ve transformada su sustancialidad metafísica del alma en la abstracción epistemológica del sujeto trascendental. Este sujeto trascendental es el titular del conocimiento y la acción, racionalmente fundadas en lo que hace a la razón pura teórica y a la razón pura práctica, y es también titular del pensamiento racional que excede las posibilidades de conocimiento de la razón misma, la dimensión metafísica del pensamiento que es coextensiva a la misma razón del sujeto trascendental, que en la corriente principal del pensamiento de Kant y del kantismo parece quedar identificada con la condición humana.

La universalidad abstracta de este sujeto trascendental, en cuanto titular de la razón y por tanto del conocimiento, la acción y el pensamiento racionales, dice de modo renovado acerca del no lugar de la filosofía en la sociedad. La filosofía estrictamente tal se despliega en la razón cuyo titular es el sujeto trascendental, por lo cual lo hace en un plano de abstracción que trasciende las condiciones históricosociales objetivas, producto de una trascendentalización (ilegítima) del sujeto empírico e histórico desde esas condiciones.

\section{Hegel: la filosofía es la época puesta en pensamiento}

F rente a la abstracción metafísica del sujeto cartesiano y la abstracción epistemológica del sujeto kantiano, Hegel desarrolla una construcción conceptual del sujeto prekantiano en su costado ontológico y poskantiano en su tensionalmente complementario costado histórico.

Hegel retorna a la metafísica y la incluye en la Historia. Uno de los títulos de las Lecciones de la historia de la filosofía de Hegel se refiere a "la filosofía como pensamiento de su tiempo". Esto implica colocar a la filosofía en la temporalidad en cuanto pensamiento relativo a la época en el cual se expresa, pero también como pensamiento a través del cual esa época se expresa en el nivel del concepto, alcanzando la mayor autoconciencia posible. Pero la temporalidad que impresiona, como la historicidad de los sujetos actuantes y pensantes que parecen alcanzar desde sí mismos y por sí mismos ese nivel filosófico de la autoconciencia que dice acerca del 
lugar de la filosofía en la sociedad y de su protagonismo parece responder a la última instancia del espíritu absoluto, que como fundamento ontológico encuentra en los agentes humanos y su historicidad meras mediaciones para presentar y representar como posibilidad lo que no ha dejado de ser metafísica necesidad. "La filosofía como pensamiento de su tiempo", no obstante aparece en la sociedad y parece tener un lugar en ella en los parámetros de su historicidad, reside en su funda- mento último en el espíritu absoluto, lo cual implica una radical exterioridad y autonomía respecto de cualquier lugar social en términos históricos y empíricos. La filosofía, descle este (no) lugar social, viene además después que el tiempo ha transcurrido para explicar-legitimar lo acontecido desde un presente en que la autoconciencia implica reconciliación del espíritu consigo mismo en su última figura que se expresa en la mismísima filosofía de Hegel.

\section{Marx: el lugar estructural de la filosofía}

A Ilí donde Hegel postuló el espíritu absoluto como fundamento ontológico subyacente del acaecer histórico, Marx argumentó en términos de la estructura o base real en su condición de producto de las relaciones objetivas y no voluntarias que los seres humanos contraen entre sí para producir materialmente sus medios de vida y de esta manera reproducir su vida misma. A esa estructura o base real material -constituida por las relaciones de producción en tensión con las fuerzas productivas materiales respecto de las que son sus condiciones de posibilidad/imposibilidad - se corresponde una superestructura institucional que tiene que ver con formas de organización social solidarias con esa base real y una superestructura ideológica en principio también solidaria con la estructura y las instituciones, con función de orientación explicativo- interpretativo-normativa para el conjunto de la sociedad, que se traduce en última instancia como función de legitimación.

La filosofía se encuentra en este lugar de la superestructura: la ideología, y esto hace que, de acuerdo a la lógica de reproducción de la totalidad estructural-institucional-ideológica, cumpla en el nivel del concepto aquella función explicativo-interpretativo-normativa, $y$, por lo tanto, en principio legitimatoria de la totalidad concreta en curso, función que cumplen en otros niveles y de otras maneras otras actividades superestructurales sociales. En esta lectura, la transformación del mundo a que convoca la tesis XI de Marx sobre Feuerbach - convocatoria de una radical modernidad, por lo que dice acerca del protagonismo de los agentes humanos en esa transformación de sus condiciones estructurales 
e institucionales de vida, $y$, por lo tanto, de sí mismos como sociedad humana, como sociedad de clases y como individuos - parece dejar a la filosofía sin papel, $y$, por lo tanto, sin lugar en ese eventual proceso de transformación.

En esta lectura de Marx, la filosofía, al igual que en Hegel, pero sobre otros fundamentos, queda identificada como saber de legitimación de lo dado y resulta descalificada como saber de transformación. Esta transformación solamente puede esperarse de la praxis de un sujeto revolucionario, que no es su- jeto de la historia sino de la praxis revolucionaria, en la que van en juego las transformaciones históricas $y$, por lo tanto, de todos los agentes humanos, incluido el mismo sujeto de la praxis.

En otra dirección, la lectura que de Marx efectúa Gramsci permite habilitar una transformación de la filosofía y hacer lugar a una filosofía de transformación: la filosofía de la praxis, que supone la doble dirección que implica potenciación, tanto de la filosofía como de la praxis, la que va de la praxis a la filosofía y la que lo hace desde la filosofía a la praxis.

\section{El lugar social de la filosofía desde algunas claves aportadas por el pensamiento filosófico en América Latina: Ardao, Roig y Hinkelammert}

\section{1. a filosofía actual en Amé- rica Latina" fue uno de los temas tratados en el Pri-} mer Coloquio Nacional de Filosofía, realizado en Morelia, Michoacán, México, en 1975. Entonces, Arturo Ardao contribuyó al debate con su ponencia "Función actual de la filosofía en Latinoamérica".

En dicho trabajo, Ardao distingue entre la filosofía como "saber filosófico" y su transmisión, la que identifica centralmente como "cuestión pedagógica", y la filosofía como "pensar filosófico", y, por lo tanto, como creación, que estima más propiamente como "cuestión filosófica". Pone en relación el concepto de "función" con el concepto de "estructura" para indicar que "la filosofía no puede menos que operar como fenómeno social, condicionado al mismo tiempo que condicionante", de manera que:

"...en tanto condicionada, la filosofía recepciona y asume procesos que se remontan desde la infraestructura material, bioeconómica; y en tanto condicionante, trasmite y rige procesos que descienden desde la superestructura intelectual, científico-ideológica. En uno y otro caso también, el entrecruzamiento socialmente más significativo se produce, cualquiera que sea la dirección o el sentido de los procesos, 
en los campos de la educación y la política. En uno y otro caso, en fin, las relaciones de dominio - o de dependencia, según se las mire- entre los sectores o grupos que forman parte de los sistemas o estructuras, se vuelven decisivas en el juego de los condicionamientos. Tanto, que son ellas, en definitiva, las que de modo más directo dan carácter a la función de la filosoffa. Explícita o implícitamente, como consecuencia, el propio filosofar resulta tironeado desde los opuestos extremos para servir, con mayor o menor eficacia, de agente intelectual de dominación o de emancipación."

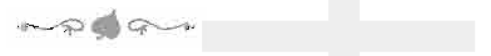

Distinguiendo dos ejes de condicionamientos que se entrecruzan y sobredeterminan, el "vertical", relativo a relaciones de clases sociales, y el "horizontal", que hace a las relaciones entre naciones y regiones y en la comprensión de que la lógica de los condicionamientos, es la tensionalidad dominación-emancipación, se sigue que, estructuralmente hablando, la filosofía no puede escapar a cumplir una u otra función:

\section{ins bacm}

"Un momento histórico llega, entonces, en las áreas dominadas, de situación límite para la función de la filosofía. En un tipo o forma de la misma, exteriormente dependiente, con conciencia o sin ella, opera en lo interno como filosofía de dominación. A la inversa, toda filosofía de emancipación nacional o regional, obligada a profundizarse, es reconducida a la radicalización social y humana - y por ende a la universalidad- de la emancipación misma."

Como para Marx, el lugar de la filosofía es un lugar estructural $y$, por lo tanto, para Ardao, funcional. Por el lugar que ocupa en la estructura es condicionada por ciertos procesos y condicionante de otros, y, como todos los fenómenos sociales que hacen a la dinámica estructural, está tensionada por la polarización dominación-emancipación que la constituye. A diferen- cia de la primera lectura de Marx, que propusimos como plausible, el lugar estructural de la filosofía no la determina como saber de legitimación, y, por lo tanto, no la hace constitutivamente funcional a la dominación. La adscripción a la función de dominación o a la de emancipación es una alternativa que filosóficamente puede discernirse, y si el sentido último de la filosofía es 
el discernimiento de la universalidad, en el plano teórico, y su construcción, en el plano práctico, va de suyo que la orientación legitimante de la filosofía en cuanto filosofía es la de la emancipación, que en tanto discernimiento y construcción de universalidad, no puede dejar de atender a los efectos de dominación que históricamente acompañan a todo proceso de emancipación para superarlos en referencia a la idea reguladora de un mundo sin dominación, y, por lo tanto, de la universalidad de lo humano.

Esta posibilidad de discernimiento entre dominación y emancipación y de legitimación del pensar filosófico, tanto en términos sociales como en términos filosóficos, por la adscripción a la función de emancipación que por su "radicalización social y humana" apunta "a la universalidad de la emancipación misma", acaece por un desplazamiento de la razón por la inteligencia, que por la recuperación de la relación del logos con el pathos y con el ethos, torna a la razón razonable, habilitando liberarla de los efectos antiuniversalistas de su totalización.

El ejercicio de la inteligencia filosófica es revelador de una "autonomía espiritual" que es condición, según argumenta Ardao, para que la "autonomía técnica" no implique sometimiento sino discernimiento de la razón heredada de la tradición. "Inteligencia filosófica" y "autonomía espiritual", en la argumentación de Arturo Ardao sobre la función de la filosofía, constituyen manifestaciones de autoafirmación del sujeto de la filosofía, perfectamente en línea con el "a priori antropológico" que desde Kant, y por la mediación de Hegel, caracteriza Arturo Andrés Roig como un "querernos a nosotros mismos como valiosos" $y$ "tener como valioso el conocernos a nosotros mismos" y en el cual afinca el comienzo y los recomienzos de la filosofía.

El "a priori antropológico", tal como lo asume y elabora Arturo Andrés Roig, remite la filosofía a un sujeto que no es metafísico u ontológico ni solipsistamente individual o universal, sino que es empírico, histórico, individual y colectivo, por lo cual la filosofía tiene un lugar en el colectivo social situado sin negar el papel del filósofo individualmente considerado, habida cuenta de todas las mediaciones entre el individuo $y$ la sociedad. El lugar de la filosofía es justamente un lugar social, tiene que ver con la autoafirmación de una sociedad, en todas las dimensiones que la constituyen y la hacen posible. Se trata, por lo tanto, de un lugar dinámico y dinamizador.

La referencia al sujeto empírico, histórico y colectivo que en el ejercicio del "a priori antropológico" hace lugar, sea al comienzo sea al recomienzo de la filosofía como saber normativo de autoconstrucción de sí mismo, no colide -a nuestro juicio- con la idea de sujeto trascendental tal como la fundamenta Franz Hinkelammert, sino que la supone. En la perspec- 
tiva de Hinkelammert, el sujeto es identificado como la trascendentalidad inmanente a las instituciones, estructuras y sistemas, en tensión con las cuales en tanto corporalidad apunta a su afirmación, a través de la crítica y superación de históricos efectos de negación derivados de la totalización de las mismas. Desde esta referencia al sujeto como "trascendentalidad inmanente" en el sentido de Hinkelammert, es que el sujeto empírico, histórico, individual y colectivo, en el sentido de Roig, puede afirmarse y superar los efectos no intencionales de negación de esta afirmación, por la perspectiva de trascendentalidad a las totalizaciones y por lo tanto de totalidad, condición de racionalidad crítica frente a las racionalidades fragmentarias y sus efectos de totalización.

\section{El (no) lugar de la filosofía en la sociedad: "campo intelectual", "campo cultural" y "campo del poder"}

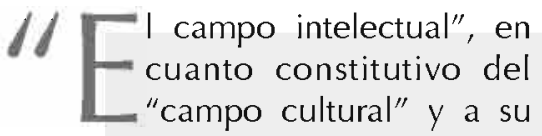
vez integrante del "campo del poder", ha venido ganando terreno frente a la tradicional referencia al "intelectual" (o a la "inteligencia") y a su protagonismo en la "cultura" $y$ en el "poder".

El "intelectual" es un sujeto, que en conjunto con otros de su especie, integra la "inteligencia", instancias individual y colectiva que protagonizan la "cultura", entendida ésta en sentido preferentemente subjetivo (las letras y las artes, la alta cultura) y por lo tanto el "poder" que implican la palabra, la escritura y el saber.

"Campo intelectual" y sus asociados "campo cultural" y "campo del poder" desacralizan ese pretendido protagonismo, al ubicar las funciones intelectual, cultural y del poder en las relaciones sociales tensionales y conflictivas en las que están involucrados los intelectuales. Además de un campo de fuerzas en el sentido de la legalidad mecánica de la física en la que no cuenta la dimensión intencional de la acción de los sujetos, se trata también de un campo de luchas en que cuenta la intencionalidad, de manera que la historicidad de los sujetos, con sus intenciones, aspiraciones, deseos, proyectos y estrategias para procurar realizarlos, se traduce tanto en efectos intencionales como en efectos no intencionales, siendo éstos últimos los que hacen a la dinámica específica del campo, más allá del pretendido protagonismo de los sujetos.

El "campo cultural" es ámbito privilegiado de construcción de hegemonía por su capacidad de potenciar las relaciones de fuerza en que se funda al invisibilizarlas tras los ropajes de la específica fuerza simbólica que caracteriza a la producción y la transmisión de la ideología, de acuerdo al primer princi- 
pio de la teoría de Pierre Bourdieu acerca de la reproducción social: "...todo poder que logra imponer significaciones e imponerlas como legítimas, disimulando las relaciones de fuerza en que se funda su propia fuerza, añade su fuerza propia; es decir, propiamente simbólica a esas relaciones de fuerza."

El "campo intelectual" identificado como "ciudad letrada" es la ciudadela al interior del "campo cultural" de la cual dimanan sus orientaciones de sentido singularmente determinantes en la construcción de hegemonía y consolidación del "campo del poder" a través de la generación de dispositivos de legitimación que llegan a instalarse en la sociedad como sentido común.

Pero, ni "campo cultural", ni "campo intelectual", ni "campo del poder" son unívocos. En particular, el "campo intelectual" en su identidad de "ciudad letrada", como campo de fuerzas y de luchas, es un campo en que se construye hegemonía y poder, pero también contrahegemonía y contrapoder. Queda claro que si bien el "campo intelectual", desde dentro del "campo cultural" y del "campo del poder", los orienta, a su vez recibe de ellos determinaciones que él traducirá desde la especificidad de sus competencias. También queda claro que estos tres campos constituyen a la totalidad social de que forman parte al tiempo que son constituidos por ella.

Dado el monopolio de la letra que el "campo intelectual" detenta a las relaciones de fuerza en que se funda, añade su propia fuerza, consistente en la capacidad de transformar la mera fuerza en legitimidad. En la dinámica de las fuerzas y las luchas que lo constituyen pueden advertirse orientaciones en el sentido de reproducción de la sociedad, así como en el sentido de su transformación: en sociedades presididas por relaciones de dominación como las vigentes, mientras las orientaciones reproductivas se abocan a presentar la fuerza como legitimidad, las orientaciones alternativas de transformación deben procurar transformar su legitimidad en fuerza.

Es, pues, constitutivo del "campo intelectual", como campo de fuerzas y de luchas, que tiene protagonismo en la construcción de relatos críticos que desnuden la mera fuerza por detrás del manto legitimador, o de relatos de legitimidad que se traduzcan en fuerza legitimada, el conflicto, la inestabilidad $y$ el dinamismo, que en la "escena intelectual" se expresa en el debate que, entre múltiples relatos, protagonizan los relatos de la reproducción y los de la transformación.

La filosofía no escapa a las luchas del campo intelectual, que hacen parte de las del campo cultural y del campo del poder que dinamiza a la sociedad como totalidad. Por lo tanto, intencional o no intencionalmente, no escapa a la disyuntiva entre reproducción y dominación o transformación y emancipación. 
Más allá de rótulos y manifiestos, la filosofía - que se construye por el ejercicio de la "inteligencia filosófica" desde el "a priori antropológico" como afirmación y autoreconocimiento de un "nosotros", sobre el referente del "sujeto" como "trascendentalidad inmanente" a estructuras, sistemas e instituciones-ocupa en la sociedad un lugar crítico-constructivo, que, aportando al discernimiento de los límites del universalismo abstracto y sus efectos de dominación vigentes, promueve su transformación frente a su lógica de reproducción, aportando a la construcción de contrapoder y contrahegemonía a la luz del no-poder, la no-hegemonía y la nodominación como ideas reguladoras y condiciones de realización de "la universalidad de la emancipación misma".

Yamandú Acosta,

Montevideo, octubre de 2006.

\section{NOTAS}

* Texto correspondiente a la ponencia presentada en el Coloquio "Crisis-Crítica-Espacio. La filosofía en el contexto actual", Facultad de Humanidades y Ciencias de la Educación, Universidad de la República, Montevideo, 17-20 de octubre de 2006.

1 Autores varios, La filosofía actual en América Latina, Grijalbo, México, 1976.

2 Ibid, pp. 9-20.

3 Ibid. P. 14.

4 Ibid. P. 14.

5 Ibid. P. 15.

6 Arturo Andrés Roig, Teoría y crítica del pensamiento latinoamericano, FCE, México, 1981, p. 11.

$7 \quad$ Franz J. Hinkelammert, Crítica a la razón utópica, DEI, Costa Rica, $2^{\mathrm{a}}$ ed., 1990.

8 Pierre Bourdieu y Jean Claude Passeron, La reproducción, Editorial Laia, Barcelona, 1977, p. 44.

9 Ángel Rama, La ciudad letrada, Ediciones del Norte, Hanover, 1984. 